\title{
UNA CONVERSACIÓN SOBRE ARTE CONTEMPORANEO Y EDUCACIÓN EN \\ CONTEXTOS DE SALUD CON JOSEP MARIA-MARTÍN. PROTOTIPO DE ESPACIO PARA LA GESTIÓN DE LAS EMOCIONES ${ }^{1}$
}

\section{Conversation with Josep María Martín about Art and Education in health context. Prototype for getting over emotions}

\author{
Marta G. Cano \\ Universidad Complutense de Madrid. (UCM) \\ martag02@pdi.ucm.es
}

Josep María-Martín es artista y profesor universitario, pero sobre todo es un hombre preocupado por conocer el mundo en que vive y generar propuestas que contribuyan a entender y mejorar los contextos en los que trabaja. El Prototipo de Espacio para la Gestión de las Emociones es un ejemplo de ello. www.josep-mariamartin.com

M. > Además de artista das clase en la universidad, de hecho eres el director pedagógico en Ginebra.

J.M.M. > He sido responsable pedagógico junto con Jean Duvendac y María La Ribot en Ginebra, pero ahora no. Ahora lo soy en Perpiñán.

M. > Das clase de diseño ¿no?. La escuela es de diseño.

J.M.M. > No, doy clases de arte. Lo que ocurre es que ahora vuelven a unirse las escuelas de arte y diseño, ese es el caso de Ginebra.

\footnotetext{
${ }^{1}$ Entrevista realizada el 9 de Mayo de 2011 en Barcelona por Marta García Cano, personal investigador del equipo del Proyecto Curarte I+D. Univ. Complutense de Madrid.
} 
M. > Y ¿cómo entiendes la pedagogía?

J.M.M. > ¿Qué es la pedagogía para mí?, la pedagogía es intentar dar desde la persona, intentar encontrar valores con ella, contrastar, asumir que siempre hay uno que sabe más que otro o tiene más experiencia y es el que debería aportar la mayor luz, creo.

Quiero hacer una pieza nueva sobre el tema de la pedagogía. Hacer una cartografía de lo que significa la libertad hoy en día y relacionarlo con la pedagogía, porque me parece que es fundamental aprender a decir no y a ser libres y a decidir con autonomía.

M. > ¿Cómo haces tus clases?

J.M.M. > La mayoría de las veces son Rendezvouz, encuentros o corrección de trabajos y muchas veces talleres. Los talleres me interesan mucho. En muchas ocasiones los talleres se convierten en piezas. Se trata de responder desde el individuo a preguntas que nos hacemos. Empiezo lanzando una pregunta, con la cual cada uno trata de buscar, por el medio que sea, toda la información que quiera y al día siguiente todo el mundo viene, como en una mesa de redacción, y pone sobre la mesa que es lo que ha encontrado. De manera que acabamos teniendo sobre la mesa 15 ó 20 veces más información que la que encontrarías tu solo.

Después cada uno explica que es lo que le parece interesante y a partir de ese momento y a partir de lo que también dicen otros decide que es lo que quiere desarrollar.

M. $>$ ¿Esto en Francia?

J.M.M. > Eso en los dos sitios. Hago talleres en muchos sitios, desde Japón hasta Chile. Lo que me interesa es que la gente se posicione estéticamente con relación al tema. Por ejemplo esto de la pedagogía. Yo no doy charlas. Al final hacemos un ejercicio en el que cada cual hace un análisis sobre su trabajo viendo que es lo que quería hacer en principio, que es lo que realmente ha hecho y donde se encuentran las contradicciones si las hubiera. Entonces es cuando doy mi punto de vista, pero no antes.

Otras veces introduzco el tema llevando a alguien conocedor del tema. Hicimos un Taller sobre la agenda y el tiempo ¿cómo administramos el tiempo?. Pudimos ir a la ciudad donde se hacen todos los relojes suizos a ver como se fabrica el tiempo de contar. Invitamos a un budista para hacer meditación y entrar en otro tiempo. Y después los alumnos estuvieron toda la semana juntos. Salieron cosas muy diferentes. De estos hago muchos.

Te voy a explicar cómo les explico yo a mis estudiantes que es para mí el arte.

M. > Sí, eso es un gran problema, el entender, sobre todo en estos contextos, que esto es arte.

J.M.M. > Sí, pero a mí no me importa, creo que esto es un avance del arte contemporáneo. Cómo la pieza del hospital para mi es una pieza de arte, como para el médico 
es una experiencia nueva, como para el psicólogo es una experiencia nueva, para el enfermo es otro tipo de servicio y para la institución otro y cómo todo eso puede ser al mismo tiempo. El arte ya no es como antes, un objeto que tenía una energía inmanente y ahí ya acaba y pasaba todo. Lo que me interesa, es constatar que estamos en el mundo de la complejidad y ese mundo de la complejidad cada uno tiene que interpretarlo y hay que volver a crear nuevos valores. El arte tiene que ver con el conocimiento, el conocimiento no sólo tiene que ver con lo racional sino con la experiencia acumulada, que los artistas manifiestan en forma de intuición. La intuición nos lleva a una primera pregunta que queremos responder y lo que hacemos es investigar sobre ese tema para intentar responder a esa pregunta y eso lo hacemos de manera muy diversa.

Cada vez que investigamos con relación a esa pregunta, que es algo que nos tira, nos vamos moviendo en dirección a ese lugar, el de la posible respuesta, pero hay un momento, si profundizas mucho, en el que encuentras un límite, porque ya no sabemos más sobre eso. En esa tensión, que sería encontrar el borde, el límite, el artista lo que tiene que hacer es saltar y cuando saltas hacía eso que parece el abismo es cuando el conocimiento se hace más grande. Ese trocito, ese pequeño trocito, es el arte y eso nuevo es lo que aportamos al resto. Por eso hay gente que salta y la sociedad no lo ha percibido o no lo ha hecho suyo y se queda ahí como aislado, y a lo mejor con el tiempo se recupera, por eso es muy importante que hagamos una obra que no solamente sirva para nosotros, si no que sirva para el resto, para el conjunto de la gente y eso se puede hacer desde muchos campos y en estos momento de confusión y de cambio de valores es mayor la conciencia de complejidad y por eso para llegar a ese borde necesitamos ir acompañados de mucha gente. Lo que pasa es que el salto es como la muerte lo haces sólo, y siempre tiene que ver con una pregunta íntima, aunque la respuesta sirva para todos.

M. ¿ ¿Cómo entiendes la colaboración y la participación en todos tus proyectos?

J.M.M. > A veces, lo mejor, que te puede pasar en un proyecto es que con la participación, con la colaboración, con los accidentes, surja la necesidad de girar para que llegue a un lugar en el que encuentras un paradigma nuevo. En mis proyectos intento que todo el mundo que colabora en algún momento se sienta protagonista, todos necesitamos de visibilidad. Lo que pasa es que también hay que aceptar que en esa comunidad que se crea haya gente que decide marcharse, porque tiene otros intereses o sus intereses han cambiado.

M. > Y en esas colaboraciones, en el planteamiento de los proyectos, las arquitecturas, los espacios, tienen una gran importancia. De hecho y volviendo al proyecto del hospital, lo que haces es construir un espacio con un arquitecto, un lugar.

J.M.M. > Sí, sí, un lugar con poco dinero, en un sitio con mucha tensión, que desconocía completamente.

M. > ¿Es grande el hospital de Castellón? 
J.M.M. > Sí es grande, bueno no sé cuantas camas tiene, pero es grande. Está en el centro de la ciudad y funciona bastante bien. Es entrar en un mundo completamente desconocido.

Mis piezas siempre empiezan a partir de las entrevistas. Yo no sé nada. Cuando me enfrenté a la primera pieza, la de Perpignan, yo no sabía nada acerca del hospital, me invitaron a hacer una pieza allí.

M. $>$ ¿Te invitaron porque tenías relación con ese tipo de contextos?

J.M.M. > No exactamente, la persona que lo organizaba, Isabelle Narcy, me conocía. Ella empezó este proyecto con el Ministerio de Cultura, invitó también a otros artistas, y le parecía que yo podía hacer una pieza en un pasillo. Iban a tirar el edificio y a construir un hospital nuevo. Yo había trabajado mucho con arquitectura y me parecía interesante. Le dije, "pero bueno, tu sabes cómo trabajo yo, sabemos cómo empezamos pero no sabemos cómo acabamos, y sabemos cómo empezamos y es a partir de preguntar “¿qué pasa aquí?” y ella respondió: pues vamos a ver qué pasa. Entonces empezamos con las entrevistas, y la verdad es que fue muy interesante, las entrevistas son muy interesantes. Soy muy curioso y en las entrevistas descubro otros perfiles en los que no había pensado. Mira esta taza, para mí esto es una taza que me permite beber café, pero para el que la ha hecho es un trabajo de cerámica, para el que ha cultivado el café otra cosa. Es todo un mundo y a partir de las entrevistas, alrededor de ellas, aparecen una serie de grietas. Ahí es donde yo me meto. Me interesa ver lo que no funciona y me interesa también proponer situaciones que puedan mejorar. El artista de los 90 también quería mejorar pero la mayoría de ellos creían en los dogmas políticos, y pensaban que iban a aportar la solución. Ahora nadie cree en el dogma, tenemos que aportar valores nuevos para aportar soluciones y aportando soluciones, a lo mejor, podemos generar nuevos valores.

M. > ¿Cómo realizas el acercamiento en tus entrevistas?

J.M.M. > Las entrevistas, como te decía, las comienzo preguntando cómo te llamas y a que te dedicas. Si me dices soy abogado, te pregunto, ¿qué es el derecho para ti? y a partir de eso hay una ola donde se cruza la persona con su oficio. Es una cosa indeleble que se va cruzando continuamente. Uno ve al médico que se pone la bata. Normalmente el médico es bastante rígido porque tiene que ser muy preciso, pero al mismo tiempo aparece la persona y la persona tiene opiniones personales y no profesionales y esa opinión personal que tiene ese médico finalmente tiene mucho que ver con una opinión profesional.

M. > ¿Cuántas entrevistas hiciste?

J.M.M. > Normalmente hago entre treinta y cuarenta entrevistas de una hora. En el hospital hicimos a enfermos, al director, a las enfermeras, a la comadrona. Me acuerdo de una cosa que me impresionó mucho, la comadrona decía que había estudiado para dar a luz, para ayuda a venir a la gente a la vida, pero en su mismo oficio le 
tocaba hacer abortar y aunque ella estaba de acuerdo ideológicamente con que cada uno hiciera lo que quisiera, esto le obligaba a vivir con esa contradicción. Aparecen un montón de cosas cuando hablas con la gente, otra cosa que llamó mi atención es que muchos enfermeros y enfermeras que vivía lejos al menos 20 minutos en coche afirmaban que eso, ese tiempo, les ayudaba a asimilar lo que había pasado durante el día para no llevarse esa tensión a casa.

M. > Darse un tiempo de tránsito.

J.M.M. > Y todo eso me llevó a pensar una obviedad, que un hospital es un lugar donde mueres y naces y donde las emociones se revelan de una manera natural, entonces ¿Cómo gestionamos eso? ¿Se puede hacer algo?. A partir de todo eso, pensé en el espacio. No sé por qué me interesa tanto crear espacios. Creo que en esta complejidad del mundo el espacio nos ayuda a focalizarnos más en el tema. Entonces los convoqué a todos, siempre hago un debate en torno a las propuestas. En este caso fuimos con una maqueta que trabajé con Alain Fidanza, un arquitecto suizo con el que he trabajado varias veces, me entiendo muy bien con él. Y les dijimos: después de todas las entrevistas que hemos tenido igual estaría bien tener en el hospital un espacio para gestionar las emociones ¿Piensan que tiene sentido? Yo me lo imagino así. Todas mis piezas las planteo desde un "Yo creo que, pero piensan Uds. que?. Dijeron que sí, hicieron sus aportaciones respecto a quitar o añadir y finalmente teníamos una lista de cosas que hicieron un proyecto más completo.

M. > ¿Cómo asumen en un hospital la entrada de un artista?

J.M.M. > En Castellón fue muy fácil. El artista muchas veces es el bufón de la corte y lo ven como un divertimento, a ver qué hará. En principio no se sienten cuestionados. Pero cuando haces una pieza que se centra en algo real, entonces empieza a haber problemas. Yo he tenido varias ocasiones en las que no he podido acabar.

(aquí hablamos de otros proyectos que tienen que ver con el hospital)

Cuando realmente no haces de bufón todo se vuelve más peligroso, pero el proyecto se vuelve más interesante, porque lo que hace es poner en evidencia la situación.

(Seguimos hablando de otros proyectos)

El mundo económico utiliza el arte para pagar sus culpas.

M. $>$ ¿En el caso del hospital te encontraste con trabas?.

J.M.M. > Había muchas situaciones difíciles, diría yo. Durante el tiempo que duró el proyecto se murieron tres personas. Un de ellas era un hombre de origen belga que llevaba poco tiempo en España y que tenía un cáncer de garganta. Se había fugado con una mujer y vivían en la calle. El Hospital de Castellón le aceptó para operarlo, pero el cáncer estaba muy avanzado. Cuando se enteró de que estábamos haciendo las entrevista y que estábamos construyendo el lugar, quisieron casarse allí y que lo entrevistáramos. Me dijeron que podíamos preguntar sobre lo que quisiéramos, sin tabúes. Fue una entrevista muy dura, salí llorando. Pero eran cuestiones emocionales. 
Pero también tuvimos trabas, sí, sí tuvimos. En el EACC se entró en crisis y había disputas personales que lo complicaban todo.

M. > Entonces, las dificultades, ¿venían más de fuera, que dentro del hospital?

J.M.M. > En el hospital afortunadamente contratamos a una chica que era fantástica y lo hacía funcionar.

Tenía que haber alguien que organizara todo aquello.

M. > El espacio funcionaba de dos maneras. De manera libre y programada. Algunos de ellos me llaman poderosamente la atención. ¿Cómo se gestionaba el espacio en general, pero especialmente, el que denominásteis espacio de conexión urbana?

J.M.M. > El hospital de Castellón es un lugar que acoge enfermos psiquiátricos y paliativos. En el caso de los paliativos sus familias no pueden hacer más que esperar y que mueran con el mínimo sufrimiento y la mayor dignidad. Cuando llega alguien a ser ingresado le dan una carpeta con información de lo que se puede hacer allí. Nosotros hicimos un folleto de información diciendo que a parte de los servicios del hospital, durante seis meses que era lo previsto, aunque después duró dos años, había un servicio nuevo, que ellos lo llamaban el espacio de las emociones, y que si querían utilizarlo tenían que hacer tal o cual cosa. De esa manera se enteraban. Al espacio de conexión urbana tuvimos que renunciar en favor de otros aspectos.

Pensamos mucho dónde instalarlo queríamos que se viera desde fuera como una barraca, nos parecía muy interesante que se viera provisional, porque lo que estábamos haciendo era poner en debate la importancia de las emociones en los procesos hospitalarios.

M. > En las fotografías no parece nada provisional.

J.M.M. > Sí, hombre sí.

M. > A mi esas fotos me llaman la atención y pienso ¡qué sitio más bonito!

J.M.M. > Pues aquello era un lugar completamente árido, no había nada. Había un objeto de cemento que parecía una gran tumba y una escultura de una monja que se murió, y yo pensaba jostras! Y aquí todas las ventanas dan a este jardín y aquí hay gente que se está muriendo. Y les propuse integrar el espacio del jardín. A mí me interesa mucho el tema del Feng shui y de encontrar armonías. Así que arreglamos el jardín. Y eso hizo un efecto llamada brutal, había flores, agua, plantas, bancos para sentarse y los enfermos psiquiátricos que no tenían donde ir, salían y hablaban con otros. Además, en Castellón hace muy buen clima. Pusimos una fuente de agua y cada 20 minutos había que cambiar la botella. No solamente los enfermos, los que venían al hospital de día también lo utilizaban. Muchos enfermos se estaban haciendo quimioterapia, y ellos tienen una gran necesidad de relacionarse con la naturaleza, con el sol, con sentirse parte de la vida. 
M. > Sí, de eso hay estudios científicos.

J.M.M. > Sí, a mí me pareció muy interesante. Fue un cambio brutal. Aunque con poco dinero yo hubiera hecho mucho más.

M. $>$ ¿Sigue funcionando?

J.M.M. > No sé, después me metí en lo de Chile. Y ha sido una locura.

M. > Otro lugar que me interesaba mucho era el espacio que denominasteis espacio programado. En el que había Internet, libros. Quizá porque está muy relacionado con el proyecto que llevamos a cabo en el Hospital 12 de Octubre, en el espacio de la biblioteca.

J.M.M. > En este proyecto he aprendido cómo a veces tienes que cambiarlo o renunciar a partes de él. En este caso teníamos que encontrar un equilibrio entre gastar lo mínimo posible y que estuviera construido de una manera creíble aunque fuera provisional y que la gente quiera utilizarlo en un momento muy importante de su vida. Cuando alguien está en ese proceso hospitalario, no puedes hacer cualquier cosa. Las cosas tienen credibilidad porque tienen una forma, una calidad de los materiales y por eso renunciamos al espacio de conexión urbana, no era tan importante. Por otra parte la psico-oncóloga nos había propuesto un espacio para tomar café y para fumar, y un día antes de la inauguración nos dijo el director que no podía aceptar lo de fumar. En principio ella lo había propuesto porque una gran parte del stress es cuando estás con un paciente que se está muriendo, si tienes que bajar a fumar tienes miedo de que en ese momento pase el médico o pase algo y tú no estás y por eso podía ser interesante tener un lugar cerca donde poder fumar. Pero sin embargo pasó algo que no teníamos previsto. Y es que el espacio del café era el lugar donde se encontraban las diferentes familias y eso funcionó muy bien, y el espacio internet fue brutal. El hecho de estar en el hospital no significa que tengas que estar desconectado.

M. > Entonces es verdad que la socialización en un lugar de esas características tiene mucha importancia.

J.M.M. > Sí, y eso son cosas que ellos pedían. Se hicieron valoraciones muy positivas de la experiencia. La psico-oncóloga organizó en el espacio sesiones de relajación una vez a la semana para las enfermeras. Para nosotros era muy importante que el espacio gestionara las emociones de todos incluyendo el personal. Que todo el mundo pudiera tener un lugar. En cierto sentido esos espacios antes los cubrían las capillas, pero ahora la gente ya no es tan creyente. Entre la gente que entrevistamos estaba el cura del hospital un señor de 90 años. Ahora tenemos psicólogos y otras formas de afrontar los temas. Los hospitales se han mostrado cada vez más científicos y menos humanos.

M. > Tiendo a pensar que ahora no, que ahora existe una tendencia a humanizar. 
J.M.M. > Bueno, ahora sí, en la ciencia en general hay una tendencia a humanizarse. En el hospital analicé el por qué se ponen una bata, a lo mejor antes era como protección de las infecciones pero ahora no, ahora creo que es para hacerse invisibles emocionalmente.

M. > De hecho me contó una enfermera que lo de la bata parecía una tontería pero que no lo era. Me aconsejaba que en el hospital no vistiera de determinados colores, que fuera afectuosa pero sin demasiado contacto físico, porque todo eso restaba energía. $\mathrm{Y}$ de hecho, el blanco no es exactamente un color relajante.

J.M.M. > Depende de lo que le pongas al lado. Nosotros hicimos un gran debate sobre eso, la gente quería que pintáramos de color, nosotros pintamos blanco por dentro y azul. Es complejo lo del color. Pero en relación a lo que decías antes, de tocar a la gente, hay una entrevista que le hicimos al peluquero. Los hospitales tienen un peluquero, yo no lo sabía.

M. > Yo tampoco.

J.M.M. > Sí, porque una de las cosas que es importante para los enfermos es estar bien, mantener un buen aspecto. Si, si. Este llevaba 20 años. Y una de las cosas que decía es que había gente a la que cogía cariño y cuando se morían lo sentía y que para él, tocar a alguien que se estaba muriendo era una relación extraña, de gran intimidad en momentos muy fuertes. Y era muy dura la relación que se creaba.

M. > Todas estas entrevistas ¿Están publicadas en algún sitio?

J.M.M. > El proyecto es tan intenso que el seguir después, tener la energía para buscar dinero para hacer una publicación, es muy complicado. Yo soy malo gestionando, no me gusta buscar dinero ni presentarme a becas, aunque ahora estoy empezando a hacerlo. Creo que esta sería una experiencia para publicar, pero necesitas tiempo y recursos. En mi página web podría tener mucha más información, pero tendría que ser rico para tener a alguien.

M. > Un becario generoso.

J.M.M. > Ni siquiera es un trabajo que le puedas dar a un becario. Tiene que ser alguien que sepa de comunicación que sepa meter la información correctamente. De cada pieza que hago hay toda una serie de documentos alrededor que serían muy interesantes, pero también hay que traducirlos, aquí en España no hago nada, lo hago casi todo fuera.

M. > ¿Y el EACC no editó nada?

J.M.M. > Nos gastamos todo el dinero en la experiencia. 
M. > Esta es una de las cuestiones, que esto trascienda más allá del ámbito artístico y de la pura micro política del lugar. Obviamente la experiencia se ha quedado en pacientes, médicos, enfermeras. Etc., pero que este tipo de cosas trascienda es importante, para crear referentes.

J.M.M. > Lo del salto.

M. > Efectivamente, lo del salto. Al final hacer otro tipo de publicación es un rollazo pero sería efectivo en otros ámbitos.

J.M.M. > Sí, pero es que eso es mucho trabajo y muy complejo. Cuando acabas estás agotado y necesitas salirte de ese tema y meterte en otra cosa.

M. > Sí, porque es algo personal.

J.M.M. > Es muy personal, son proyectos muy intensos, muy negociados, nunca hay suficiente dinero, yo soy muy exigente y siempre son temas candentes y acabas exhausto, yo y los que están con migo.

M. > Sí, pero por ejemplo una copia del video en La Casa Encendida o en el Reina. No está.

J.M.M. > No, no está en ningún sitio. Pero ellos tampoco se han interesado.

M. > Bueno claro es que esto del arte, los hospitales y la salud o el arte en contextos tan especiales ¿a quién le ha interesado? ¿Cuándo ha empezado a interesar?

J.M.M. > Ahora está empezando. En Inglaterra hay unas políticas muy interesantes.

M. > En Inglaterra mucho, en Francia, en Canadá hay redes importantes.

J.M.M. > Sí, pero en general son piezas que tienen que ver con la ocupación del tiempo libre, con remover. Es que mi pieza remueve cosas.

M. > Claro, remueve y destapa. Si lo trasladamos al campo científico es una investigación cualitativa y de implementación, en una gran medida. Yo esas preguntas me las hago, donde está esa barrera de estar haciendo un trabajo social, de investigación, de transformación, de arte.

J.M.M. > Pero es que el arte también es eso. Por eso te decía antes lo del conocimiento. Todos de forma diferente pretendemos hacer lo mismo que es ampliar ese conocimiento y unos utilizan unas herramientas que puede ser el trabajo social, otros otra cosa. Pero todos queremos ampliar la calidad de vida y aprender de los cambios que continuamente nos van llegando. Para que queremos ese conocimiento si no es para 
ser capaces de afrontarlos mejor, no es acumular conocimiento por acumular, sino para ser capaces de enfrentar mejor una situación diferente que va a llegar.

M. > Entender.

J.M.M. > Claro, entender nos va a posicionar delante de aquel objeto y de aquello que pasa de una manera diferente, nos va a dar más herramientas. Todos estamos creando herramientas. Unas son estéticas, que tiene que ver con las éticas emocionales, otras son políticas para cambiar sistemas otras son herramientas sociales. Todos estamos haciendo lo mismo, entonces, para que separar si es arte, sociología o no sé qué ¿por qué no vamos a la esencia?. Y eso es lo que a mí me interesa. Yo ya hace mucho tiempo que no me pregunto si es arte o no lo que hago. Para mí la estética es muy importante, las formas, lo que intento es encontrar formas nuevas. Y yo en principio tengo una formación de pintor. Formas que han ido evolucionando, queda feo decirlo, pero que tiene que ver con pintar un cuadro, pasaba algo y había una expresión, una comunicación, un aprendizaje y eso intentaba transmitirlo y ahora hago lo mismo y el lienzo blanco es el contexto social, y en eso contexto social aparecen cosas.

M. $>_{¿}$ Crees que hacerlo desde el punto de vista del artista poetiza?

J.M.M. > A diferencia del científico el artista se permite una investigación más flexible, en la puede ser contradictorio y no pasa nada y llevarte a un lugar seguramente desconocido. Por eso los artistas podemos llevar a otros lugares y llegar más allá que los científicos porque ellos tienen que demostrar, que probar, y yo no.

Si con lo de poetizar quieres decir que lo lleva a un lugar donde no hay una razón aparente, sino una razón más cartográfica de crear un estado, sí.

M. > Sí, jugar con los símbolos de otra manera. No referirte a datos solamente. Datos que se convierte en historias que son más atractivas, es como una película, no son solo datos es contar.

J.M.M. > Sí, sí, sí, pero además piensa que cuando lo haces desde el arte tiene un significado que puede ser doble o diferente a aquello que haces. Quiero decir, el hecho de hacer desde el arte, el hecho de que sea un hospital y no sea otro sitio, tiene una significación, significante busca significación y puedes buscar otro tipo de significación que no sólo sea el curarte físicamente, sino curarte de otra manera. Poner en orden de otra manera. No se sí me explico.

M. > Sí, sí, perfectamente. Me contaste por teléfono que también habías realizado una experiencia en Vic, con unas enfermeras.

J.M.M. > Huy, eso fue muy bonito. Me invitaron en el año 90. Me llamaron para hacer una pieza en la Universidad de Vic. Lo que pretendían era introducir el Arte Contemporáneo a los estudiantes de la Universidad. Éramos varios artistas, entre ellos Antonio Muntadas, pero no tenías por qué inmiscuirte en la Universidad. Yo 
en aquellos años trabajaba mucho con la idea del prototipo, que es una cosa que siempre está en mis piezas, el prototipo es algo que pones a prueba. En el fondo soy muy relativista y entonces como que las verdades definitivas, no sé. Y cuando fui a ver que podía hacer, al pasar por el departamento de enfermería vi un muñeco que utilizaban las enfermeras para hacer sus prácticas, y me pareció interesante trabajar sobre la idea del prototipo de un ser humano y les propuse una idea que llamé "El niño David" NEN DAVID. Fueron seis meses de trabajo con 5 o 6 enfermeras que estaban acabando su carrera y que con ello hicieron su proyecto final. Consistió en definir cómo podía ser un niño desde su nacimiento hasta los veinte años, cómo podía ser todo el proceso de evolución. Le hicimos desde la carta astral, hasta decidir de qué color iban a ser sus ojos, que tipo de música le iba a gustar. Hicimos entrevistas con los genetistas y les preguntamos si era posible y cómo un bebe puede ser los que nosotros queramos. Fue un debate sobre la genética, la psicología, sobre toda una serie de temas relacionados con ese ideal de niño que habíamos creado, que habíamos negociado. Y al mismo tiempo poner en duda lo que imaginas, lo que prevés que puede ser una vida, una identidad y lo que supone admitir que eso sea diferente. Al mismo tiempo fue una opción para las estudiantes de profundizar en sus estudios. Hicimos una agenda con los veinte años en la constaban todos los detalles, cuando tenía que comer, cuando tenía enfermedades, etc. Se abrió el debate. Y todo se convirtió en su trabajo final de carrera. Finalmente nos parecía importante hacer algo escultórico y visible y en aula. Oscurecimos el espacio completamente, construimos una pared de 7 metros que dividía el espacio en dos con una pared que se balanceaba como si fuera una cuna. Cuando entrabas no veías nada, oías el cra, cra, del motor y una canción de cuna japonesa, cantada por un hombre. Elegimos un hombre para evitar asociaciones que no nos interesaban. Al cabo de un rato, los ojos se acostumbraban a la luz y se empezaba a ver el muro, y en el muro había un dibujo escala uno a uno de un niño. Fuera había una guía que era la síntesis del trabajo que habían hecho las enfermeras.

Me pareció muy interesante el hacer un trabajo de estas características en el aula. Suponía añadir al trabajo de recogida de datos y al planteamiento del proyecto un aspecto emocional. Cuando se entraba en este aula al mismo tiempo creábamos una parte emocional, tiene que pasar un tiempo para que te acostumbres que es el tiempo que la madre no ve al hijo y que empieza a especular, y nosotros lo que habíamos hecho era una especulación con ese niño y en esa especulación puede llegar a cosas buenas, positivas, o a lugares muy terroríficos como es intentar imponer una forma de pensar.

M. $>$ ¿Y de eso tienes documentación, hay por ahí un pequeño catálogo?

J.M.M. > Pero esto no está puesto en la página web. Tendría que buscarlo.

M. > No conozco muchos artistas que hagan cosas en el tema de la salud.

J.M.M. > Pero yo no me centro en la salud. Me centro en temas relacionados con el desarrollo humano. 
M. > Pero además vienes de la universidad, trasladas el mismo concepto de la pedagogía, de hacer una clase, a tus proyectos. No hay diferencia entre una cosa y otra.

J.M.M. > Yo no diferencio las cosas. Pero la gente sí las diferencia.

M. > Pero a la hora de entender el conjunto yo no las diferenciaría, porque está esa vocación del aprendizaje. Tú en clase lanzas una pregunta y desde ahí el alumno se posiciona para elegir desde donde y qué quiere aprender en esa clase. Con el espacio para la gestión de las emociones generas las mismas dinámicas.

J.M.M. > Sí. Si lees mis textos siempre dicen que mis piezas tienen una vocación de aprendizaje, pero investigamos, participamos y además proponemos.

En Brasil me dijeron que la tendencia ahora es no construir más hospitales sino crear grupos de médicos, que van a las casas porque es mejor atenderlos en las casas, hay muchas tendencias, eso lo hicieron también por el tema emocional. Nosotros en este proyecto de Castellón, siempre queríamos hacer un lugar de transición entre el hospital y la casa, porque la casa te da una cosa y el hospital otra. La casa te da el espacio de acogida que necesitas y el hospital la seguridad de que te van a atender.

M. > Y de incertidumbre. Una gran incertidumbre, la espera. Es un lugar en que esperas a curarte, esperas a que venga el médico, esperas a que vengan a visitarte. Estas esperando todo el tiempo.

J.M.M. > Si, es verdad. ¿Sabes? Cuando la presentamos en Madrid la titulamos ¿Hasta cuándo?. Es la frase literal de una trabajadora social que trabajaba con los enfermos psiquiátricos. Decía que lo primero es hacerte cargo de que estas enfermo y eso cuesta mucho trabajo, y una vez asumido empiezan a preguntarse hasta cuándo y nadie sabe responder a esa pregunta que puede ser toda la vida. Todos vamos a estar en el hospital en algún momento, todos vamos a acompañar a alguien y los hospitales tiene algo que tienen los aeropuertos, esos macro servicios, en la cárcel también, donde hay un silencio extraño, el tiempo pasa de otra manera. Uno es prisionero de algo. Cuando alguien muere tienen una sensación de liberación, como cuando sales de la cárcel.

Tiene que ver con el tiempo, hay diferentes tiempos. Una cosa es el tiempo de la vida cotidiana y otra el tiempo del cuerpo, en los hospitales está el tiempo del cuerpo. Te ponen una inyección y tiene que reaccionar, hay una parte que tiene que ver con la capacidad de asimilación que tiene tu cuerpo. Hay también una parte emocional y no se puede separar. En este sentido el espacio para gestionar las emociones también es un espacio de tiempo, la mejor manera de gestionar las emociones es tener tiempo para ir asimilando y cuantos más recursos tengas, tu cuerpo reaccionará más rápido. Me parecía interesante por un lado que la institución reconozca las emociones como algo a tener en cuenta y por otro el hecho de que tanto la institución como las personas supieran que a lo mejor el espacio te puede ayudar. Porque la realidad es que ese espacio no es necesario la gestión de las emociones pasa en el tiempo, no en el espacio, el espacio te va a ayudar. Nosotros estamos aquí y este lugar nos ayuda a 
poder comunicarnos, eso no quiere decir que fuera no podamos hablar, pero las interferencias serían mayores. Estar aquí nos facilita la comunicación.

M. > Después de esos seis meses que estaban previstos, el funcionamiento se prolongó, ¿siguió la persona que teníais en un principio contratada para esto? ¿Quién la pagaba, el propio hospital?

J.M.M. > Sí. El hospital puso dinero, pero yo creo que eso ahora no se haría así. También llegamos a un acuerdo con la biblioteca municipal y los pacientes podían pedir libros y películas y también desde la biblioteca proponían cosas.

M. > ¿Y la colaboración con los médicos?

J.M.M. > Los médicos son difíciles.

M. $>i Y$ las enfermeras?

J.M.M. > Menos, son menos arrogantes. Aunque ahora que lo dices yo tuve problemas con las enfermeras. Porque les molestaba, y con razón, que estuviéramos construyendo al lado de gente que se estaba muriendo. Qué difícil convivir con eso. Ellas no lo entendían. Gastarse tanto dinero para eso. Pero al final vieron la importancia y se sentían orgullosos. Y eso es una cosa muy importante.

M. > Eso es fundamental, esa es la micro política. Hay un lugar donde alguien ha tomado conciencia de que todo eso es importante.

J.M.M. > Sí, sí y todo eso fue posible porque el comisario, Juan de Nieves, que en ese momento era director del EACC, es una persona interesada en este tipo de proyectos, así, menos museables por decirlo de alguna manera. Y él se implicó muchísimo, si no, no hubiera sido posible.

Y otra cosa, que no te he dicho y que es muy importante para mí, es que yo no he ido a proponer el proyecto. Es muy diferente que te pidan a que tú tengas que pedir, eso también facilita. Alguien tiene que haber que te apoye.

M. > Cuéntame cómo desarrollásteis el proyecto desde un principio.

(Me enseña el proyecto en su ordenador, comentando las imágenes) 


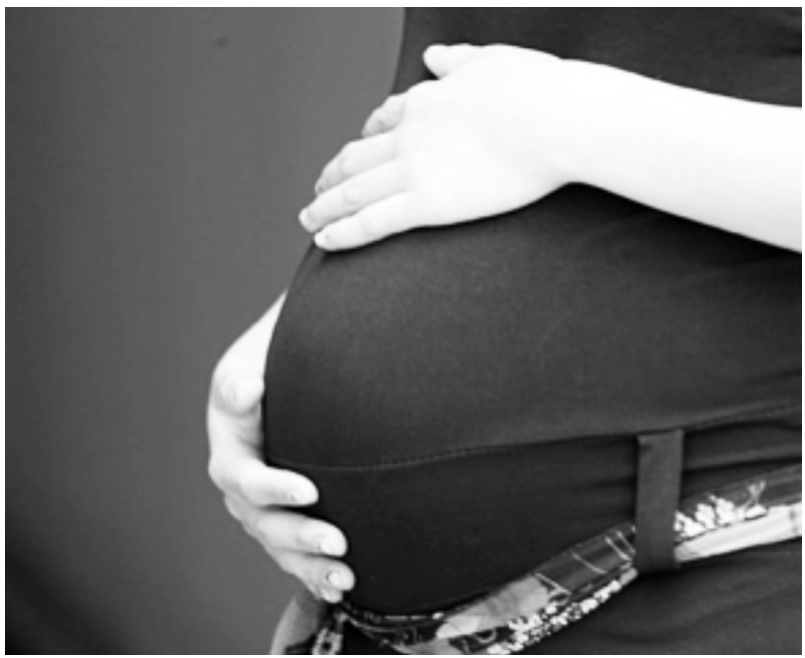

J.M.M.> Cuando trabajamos siempre buscamos una imagen que nos sirva de referencia. $\mathrm{Y}$ en nuestro caso fue la imagen de esta mujer embarazada. Una mujer que pone todo su cuerpo a disposición para que desde un embrión nazca un niño.

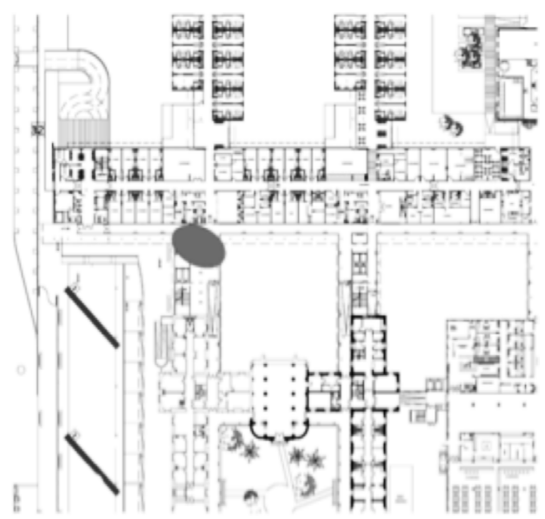

J.M.M. > Queríamos hacer una especie de célula en este cruce entre la entrada y el jardín y la unidad de enfermos paliativos que estaba en la planta de arriba y que resultaba muy importante.

La propuesta fue construir cinco espacios diferentes, 1. Programado 2. Convivencia. 3. Internet. 4. Tabaco / café que finalmente se quedó sólo en café. Y 5. Conexión urbana al que renunciamos.

Estos son los dibujos que hicimos, complicado ¿no? 
J.M.M. > Pensamos así. Lo más importante que pasa aquí es la persona que entra. Y esa persona emana unos radios. Queríamos hacer visible simbólicamente eso. Además el espacio de acción que era lo que llamamos el espacio programado, el espacio de entrada al conflicto, era un escenario que tenía que ser como un estómago, y que se iba acomodando en relación a cómo iba a ser utilizado y debía estar equipado con todo lo que pudiera hacer falta y fuera fácil de mantener.

Sin darnos cuenta creamos un sistema orgánico. El estómago, los riñones el hígado.

Y desde aquí había una gran cristalera, como te decía antes la gestión de las emociones pasa por el acercamiento a la naturaleza por eso esta parte que era la que daba al jardín se volvía muy importante.

La cuestión simbólica para mí era muy importante, lo poético que tú dices. Me interesa mucho Japón y como estábamos en un lugar que tenía que ver con los enfermos paliativos me acordé del Origami que hacía Sadako Sasaki y me pareció que lo que teníamos que hacer era algo que hiciera referencia a ese lugar de esperanza, como la esperanza de Sadako Sasaki.

Origami quiere decir papel plegado.Este es el primer prototipo del espacio que hicimos que era como el nido de las grullas de Sadako, aquí los rayos estan reflejados por paneles. Al final renunciamos a esto por el coste.

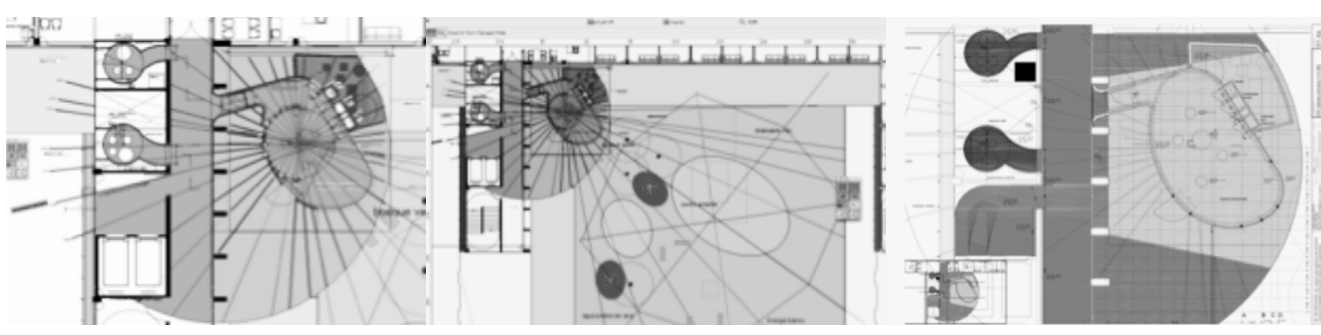

M. > ¿Encontraste similitud en los resultados entre Perpignan y Castellón?

J.M.M. > No, aquí fue mucho mejor porque teníamos una persona que lo gestionaba. Y además teníamos mucha experiencia, en el primero todo era mucho más intuitivo. Fuimos buscando como construir ese espacio de manera posible. Es un proceso complejo. Nos gustaba mucho la idea de papel y que se viera frágil por fuera.

Y una parte del espacio lo ganábamos haciendo un falso techo y nos metíamos en el jardín que era muy interesante.

Sí, por fuera tenía que parecer inacabado. Por dentro tenía que ser perfecto, lo que uno no tiene que hacer es plantearse nada sobre el espacio, solo estar ahí viviendo esa emoción. No hay que intelectualizarlo. 


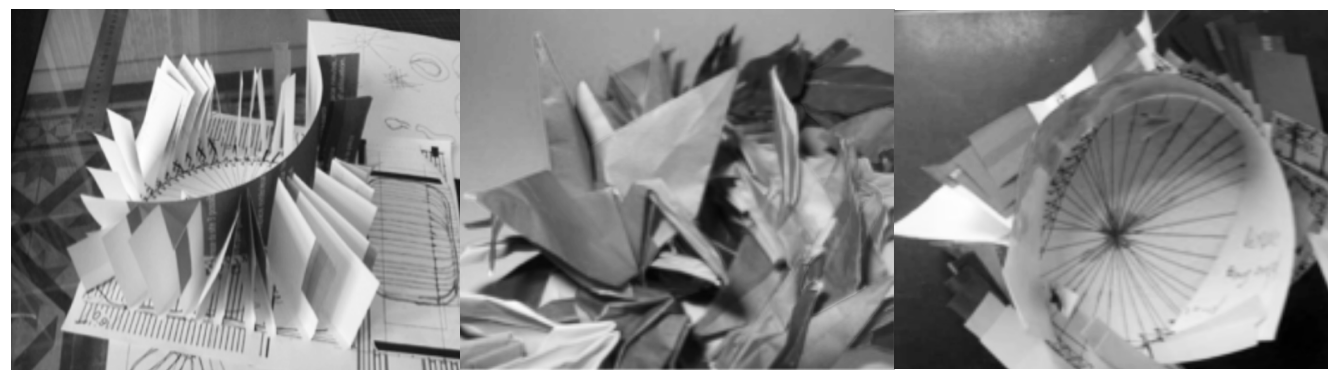

J.M.M. > Lo que hicimos fue remarcar toda la parte emocional con una capa de pintura que dijera Uds. Están entrando a un espacio diferente.

Creamos una comisión que se reunía cada semana y yo iba una vez al mes, para ver ir valorando. Y la idea era ser muy críticos para mejorar. La valoración fue fantástica.

El espacio de convivencia, un espacio relacionado con la naturaleza.
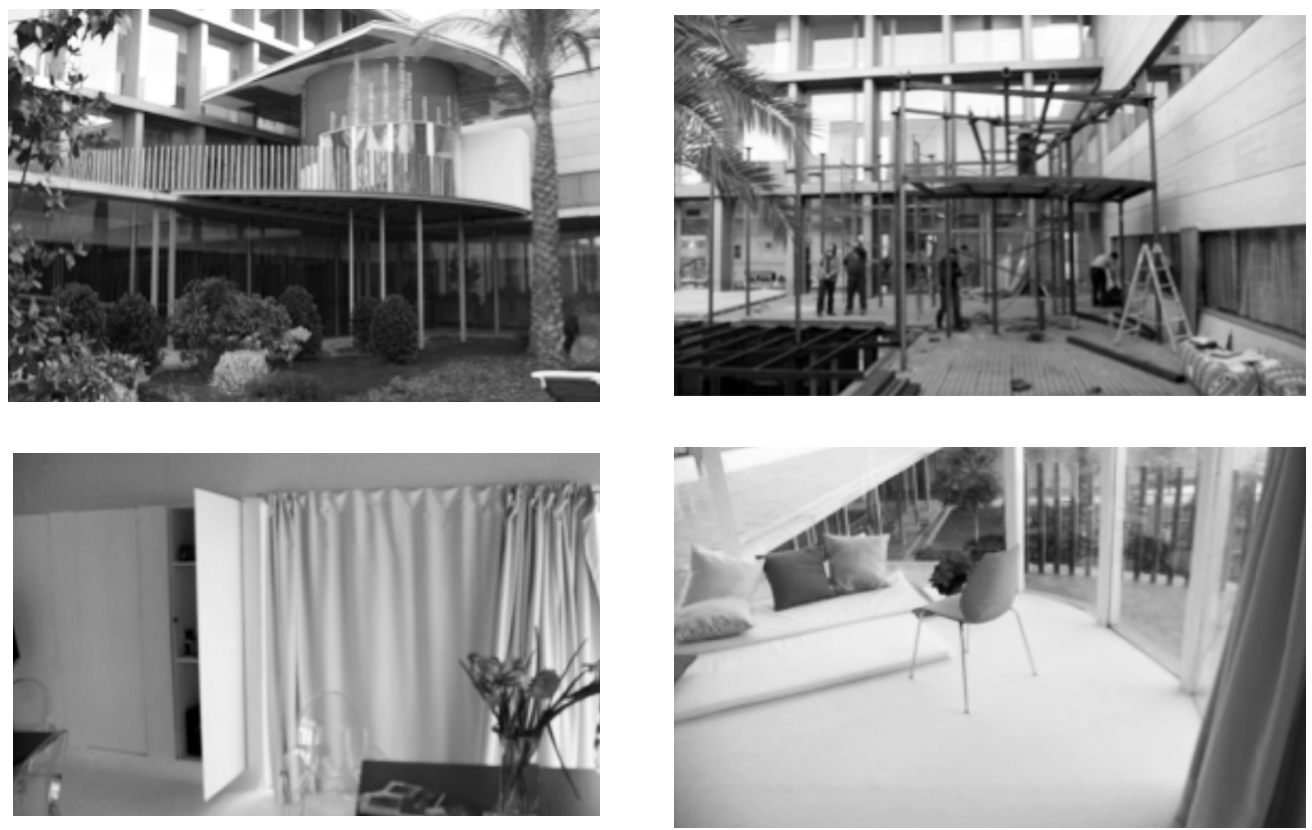

J.M.M. > Me parecía que era como un cementerio. Y con el mínimo dinero posible y mucho trabajo lo convertimos en esto. Yo quería que fuese salvaje. 

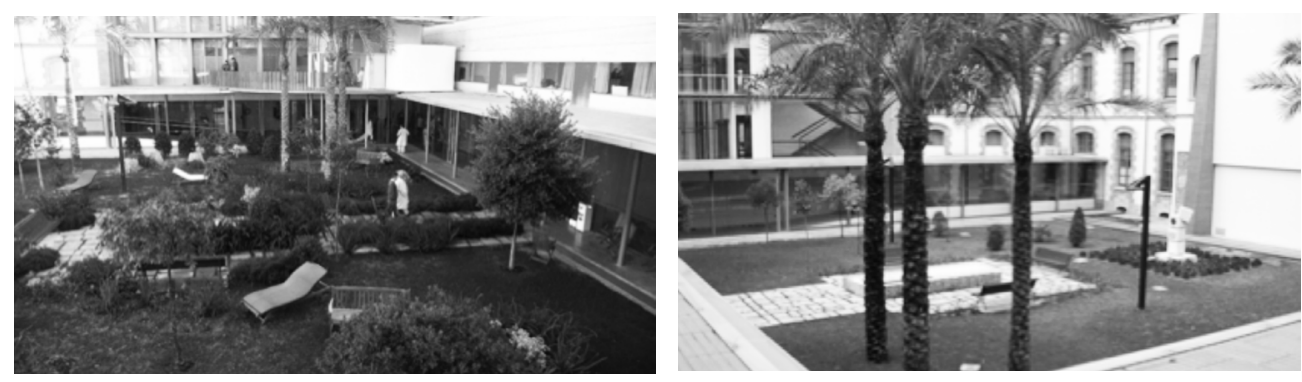

J.M.M. > El espacio café y el espacio Internet fueron muy utilizados siempre.

Y se hizo un documental que duró más de 5 horas, en el que se recogían todas las partes de las entrevistas y que no se repitieran una con otra. Es decir, lo que tenía cada una de diferente. Las entrevistas se pusieron en la pared para que la gente pudiera escucharlas.

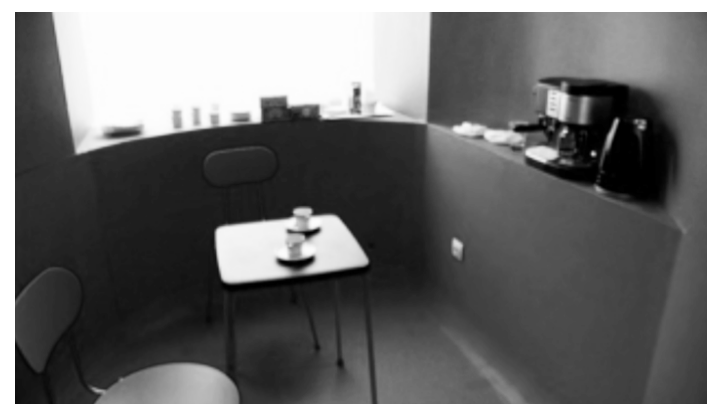

M. $>$ ¿Y qué hace un proyecto como este en Arco? Yo diría que casi es un entorno un poco hostil para un proyecto de estas características.

J.M.M. > Yo lo hice aposta. Nunca presentaría en un "fast food" como ARCO una pieza que habla del tiempo y menos en una feria que abre 10 horas con una pieza que dura casi seis. Me parecía interesante que hubiera una crítica a que el arte no es solo consumir rápido, sino que hay procesos que son más lentos.

M. > ¿Por qué el Espacio de Castellón no decidió hacer una exposición con el proyecto?

J.M.M. > Porque se marchó el director Juan de Nieves y las personas que han seguido no estaban interesadas en eso.

M. $>$ ¿Y llevarlo a algún lugar expositivo, que en definitiva también es un lugar de difusión? 
J.M.M. > El museo es un lugar que tiene que ver más con constatar y catalogar algo, construir una referencia para los demás. Estaba previsto, pero al irse esa persona, haber hecho un catálogo hubiera supuesto dar importancia al trabajo que esa persona estaba haciendo y darle más visibilidad de la que querían darle. Pero yo creo que ya que se invirtió tanto hubiera sido bueno sacarle rentabilidad.

M. > Sí, rentabilidad y difusión, en definitiva un museo y un centro de arte también tienen esa función. Una función social.

J.M.M. > Sí, no hablo de rentabilidad económica, sino de conocimiento. 